\title{
Comparison of the Evapotranspirations among a Paddy Field, Cassava Plantation and Teak Plantation in Thailand
}

\author{
Pedram ATTAROD*, Daisuke KOMORI*, Kazushi HAYASHI", Masatoshi AOKI*, \\ Tomoyasu ISHIDA $^{* *}$, Kazunari FUKUMURA ${ }^{* *}$, Samakkee BOONYAWAT ${ }^{* * *}$, Panya \\ POLSAN $^{* * *}$, Piyapong TONGDEENOK ${ }^{* * *}$, Promsen SOMBOON $^{* * *}$ and Somnimitr \\ PUNKNGUM ${ }^{* *}$ \\ *Faculty of Agriculture, Tokyo University of Agriculture and Technology, Tokyo 183-8509, JAPAN \\ *."Faculty of Agriculture, Utsunomiya University, Tochigi 321-8505, JAPAN \\ -.. Faculty of Forestry, Kassetsart University, Bangkok 10900, THAILAND \\ *.** Hydrology and Water Management of Northern, Royal Irrigation Department, Phisanulok 65000, \\ THAILAND
}

\begin{abstract}
Evapotranspiration (ET) is an essential factor for estimating crop water use. It is also one of the factors in soil water storage and water resource in a region. This study is to compare the trend of actual evapotranspiration (AET) and crop factor $\left(\mathrm{K}_{\mathrm{c}}\right)$ among three measurement sites in Thailand that are a rain-fed paddy field, cassava plantation and teak plantation. Bowen ratio energy balance technique (BREB) was applied in this investigation to measure the AET and heat flux between ground surface and atmosphere. The Penman-Monteith equation recommended by FAO was used to calculate crop coefficients. Measurements were carried out during 1999-2003 in the paddy field, 1999-2002 in the teak plantation and 2002-2003 in the cassava plantation. Results showed that the amount of daytime AET during the rainy season in the paddy field and cassava plantation varied between 1 and $7 \mathrm{~mm} /$ daytime and in the teak plantation between 2 and $6 \mathrm{~mm} /$ daytime. The average amount of daytime AET in the rainy season was about $4 \mathrm{~mm}$ in all sites although the variations of AET were different. In the dry season, AET of the teak plantation was around $3.2 \mathrm{~mm} /$ daytime, slightly higher than those of other sites. During the growing season, the $\mathrm{K}_{\mathrm{c}}$ factor varied in the paddy between 0.4 and 1.2 and in the cassava between 0.3 and 1.2. Variation of the $K_{c}$ factor in the teak plantation was smaller than those of the others. In the rainy season, the $L E / R_{n}$ ratio in the cassava plantation and the paddy field was around $70 \%$ but in the teak plantation it was about $77 \%$. The $\mathrm{K}_{\mathrm{c}}$ factor in the paddy field was more affected by soil moisture than at other sites.
\end{abstract}

Keywords: Actual evapotranspiration, Cassava plantation, Crop factor, Paddy field, Teak plantation

\section{Introduction}

Thailand is located in the tropical Asian Monsoon region. The dry season begins in November and ends in April. Rice, cassava and teak are among the most important crops and timber production trees which cover a large portion of land use in the Chao Phraya River basin and North-East region of Thailand. In artificial and natural ecosystems including agricultural lands, it is essential to evaluate the evapotranspiration (ET) for developing more efficient and sustainable water management techniques and planning of irrigation scheduling. Also vegetative productivity is closely related to ET. The crop coefficient $K_{c}$ is the ratio of actual evapotranspiration (AET) to the reference evapotranspiration $\left(\mathrm{ET}_{0}\right)$ calculated by the FAO Penman-Monteith method (Allen et al., 1998). $\mathrm{K}_{\mathrm{c}}$ values can be useful to plan the irrigation scheduling in the tropical Asian Monsoon region. Since researches on the ET and $\mathrm{K}_{\mathrm{c}}$ values in the tropical region are relatively scarce, the objective of the present study is thus to find out the trend of ET and crop factors in three crop covers including a rain-fed paddy field, cassava plantation and teak plantation in Thailand and also comparison of ET values among the mentioned vegetations. Bowen ratio method was employed to estimate crop ET and calculate crop evapotranspiration because of its relatively cheapness compared with the other micrometeorological techniques. (Casa.R, 2000)

\section{Materials and methods}

\subsection{Experimental sites and plants}

The measurements were carried out at three measurement sites in Thailand, a rain-fed paddy field in Sukhothai province $\left(17^{\circ} 03^{\prime} \mathrm{N}, 99^{\circ} 42^{\prime} \mathrm{E}\right.$, elevation $50 \mathrm{MSL}$ ), a cassava plantation near Nakhonratchasima $\left(14^{\circ} 47^{\prime} \mathrm{N}, 102^{\circ} 38^{\prime} \mathrm{E}\right.$, elevation $\left.311 \mathrm{MSL}\right)$ and a teak plantation in Lampang province $\left(18^{\circ}, 40^{\prime} \mathrm{N}, 99^{\circ} 47^{\prime} \mathrm{E}\right.$, elevation $241 \mathrm{MSL}$ ) which are GAME-T and CEOP project sites. Measurements were performed during 1999-2003 in the paddy field, 1999-2002 in the teak 
plantation and 2002-2003 in the cassava plantation. Measurement sites of paddy field and cassava were selected in farmer lands. Rice seeds are sown every year by a farmer after the start of rainfall period in late July and harvested at the end of November. Cassava is also planted mostly every year in March and harvested in the dry season and grown without irrigation. Teak, a 38-year deciduous plantation, mostly starts to open leaves in May and the leaves start to shed in January. At each field, microclimate measurements have been carrying out using an automatic weather station system developed by Aoki, et al. (1996)

\subsection{Evapotranspiration}

The Bowen ratio energy balance system (BREBS) was employed to measure AET. The dry and wet-bulb temperatures were measured at two levels above the canopy (paddy, cassava: $1-3$ and $10 \mathrm{~m}$; teak: 12 and $24 \mathrm{~m}$ ) using a hand made 10 paired copper-constantan thermocouple thermometer (shielded and ventilated). The instruments were installed on a $10 \mathrm{~m}$ tower in the paddy field and cassava plantation and on a $24 \mathrm{~m}$ tower in the teak plantation. A net radiometer (MF -11 EKO) was used above the canopy to measure the net radiation flux density. The fetches are around $500 \mathrm{~m}$ in the paddy field, at least $2 \mathrm{~km}$ in the cassava plantation and $400 \mathrm{~m}$ in the teak plantation. Two or three heat flux plates (P-MF-81, EKO) were placed at $1 \mathrm{~cm}$ in the soil surface. Two tensiometers were also set at $15 \mathrm{~cm}$ depth in soil near the tower of ET measurement. Their instantaneous data of every one minute were collected by a data logger to get ten minutes average, and all data were finally averaged into the daytime mean $\left(R_{n}\right.$ positive). Daytime latent heat flux was calculated from the equation:

$$
L E=\left(R_{n}-G-G_{w}\right) /(1+\beta)
$$

in which $R_{n}\left(\mathrm{MJm}^{-2} /\right.$ daytime) is the net radiation, $G$ $\left(\mathrm{MJm}^{-2} /\right.$ daytime) soil heat flux, and $\mathrm{G}_{\mathrm{w}}$ $\left(\mathrm{MJm}^{-2} /\right.$ daytime) heat flux in water (paddy field). The daytime latent heat flux (LE) was then converted into the daily actual evapotranspiration (AET) in $\mathrm{mm}$ per daytime. The average contribution of the latent heat flux to net radiation $\left(L E / R_{n}\right)$ was calculated to understand the energy allocation to the evapotranspiration process. (Peacock. C.E, 2004)

2.3. Reference evpotranspiration and Crop coefficient

Daily reference crop evapotranspiration $\left(\mathrm{ET}_{0}\right)$ was calculated using the form of the Penman-Monteith equation recommended by the FAO (Allen, et al., 1998) for a hypothetical grass crop with an assumed height of $0.12 \mathrm{~m}$, a fixed surface resistance $\left(70 \mathrm{sm}^{-1}\right)$ and an albedo (0.23) as follows:

$$
E T_{0}=\frac{\left.0.408 \Delta\left(R_{n}-G\right)+\gamma(900 / T+273)\right) u_{2}\left(e_{s}-e_{a}\right)}{\Delta+\gamma\left(1+0.34 u_{2}\right)}
$$

where $\mathrm{T}$ the daily air temperature $\left({ }^{\circ} \mathrm{C}\right), \mathrm{u}_{2}$ wind speed at the height of $2 \mathrm{~m}\left(\mathrm{~ms}^{-1}\right)$, $e_{\mathrm{s}}$ the saturation vapor -pressure (kpa), $e_{a}$ the actual vapor pressure $(\mathrm{Kpa}), \Delta$ is the slope of the vapor pressure curve $\left(\mathrm{kPa}^{\circ} \mathrm{C}^{-1}\right)$, and $\gamma$ is the psychrometric constant $\left(\mathrm{kPa}^{\circ} \mathrm{C}^{-1}\right)$. Daily average values for each crop were used for $R_{n}, T$ and $e_{a}$. To calculate the wind speed at $2 \mathrm{~m}$ above the surface, the wind speed data were converted by the following equation recommended by $\mathrm{FAO}$ :

$$
u_{2}=u_{z}(4.87 / \ln (67.8 z-5.42))
$$

where $u_{2}$ measured wind speed at $2 \mathrm{~m}$ above ground surface $\left(\mathrm{ms}^{-1}\right), \mathrm{u}_{\mathrm{z}}$ measured wind speed at $\mathrm{z} \mathrm{m}$ above ground surface $\left(\mathrm{ms}^{-1}\right)$ and $z$ height of measurement above ground surface $(m)$. Crop coefficients $\left(K_{c}\right)$ for paddy field, cassava and teak plantations were calculated using the relation $\mathrm{K}_{\mathrm{c}}=\mathrm{AET} / \mathrm{ET}_{0}$.

\section{Results and discussion}

\subsection{Seasonal change in evapotranspiration}

Figurel shows seasonal changes in daily AET
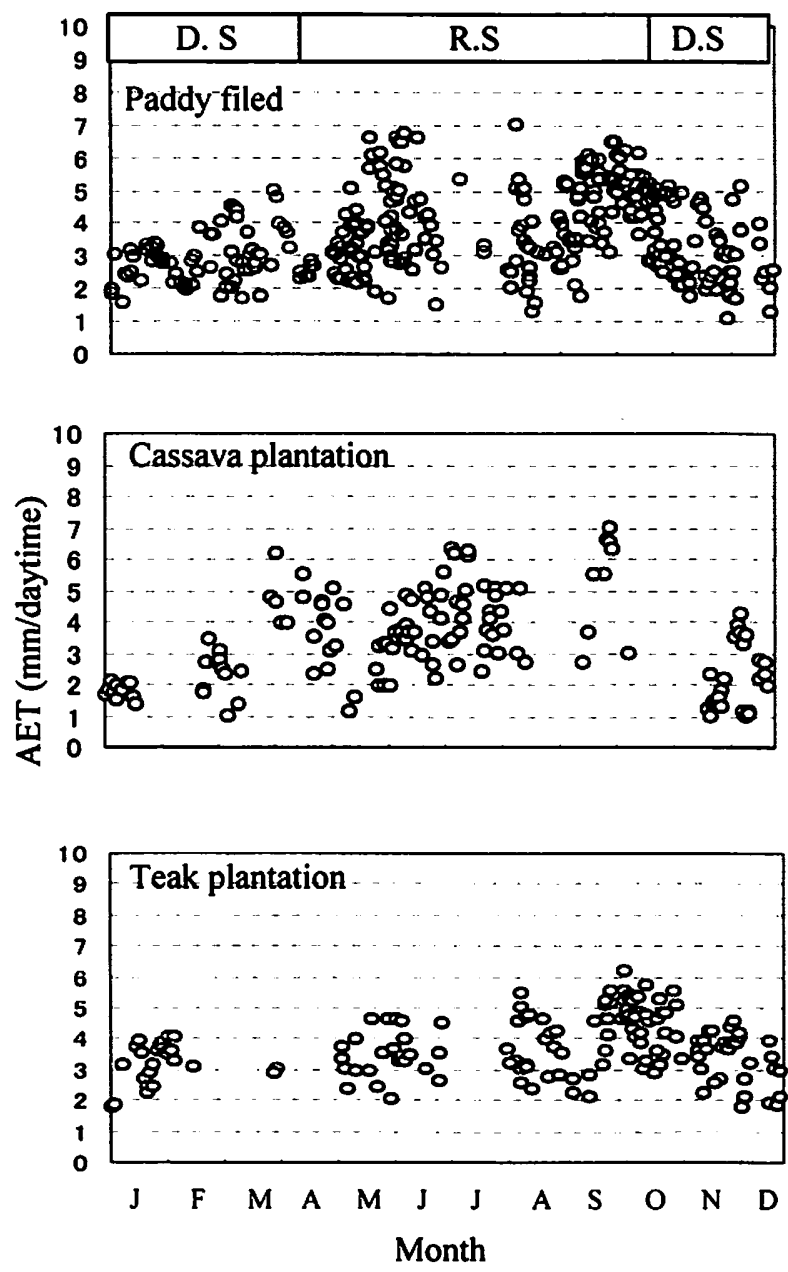

Fig.1. Seasonal change in daily evapotranspiration for the paddy field, cassava and teak plantations (D.S: Dry Season and R.S: Rainy Season ).

expressed in a year for the paddy field taken from June 1999 to Dec. 2003, for the cassava plantation from May 2002 to Dec. 2003 and for the teak for 
plantation from May 1999 to Dec. 2002. AET in Jan. was lowest in three sites (Average; paddy: $2.7 \mathrm{~mm}$; cassava: $1.7 \mathrm{~mm}$; teak: $3 \mathrm{~mm}$ ). It started to increase around May (Average: $3.2 \mathrm{~mm}$ in all sites) when the growing season started, and reached its peak (average $=4.5 \mathrm{~mm}$ in all sites) during the mid growing season in Sept. and Oct. Increase in net radiation and $L E / R_{n}$ ratio in May and April might increase the evaporation from the submerged water in paddy field before starting the growing season. Increase in the AET of cassava in May and April is explained by the presence of the plants before starting the rainy season. The peak of AET in three sites synchronized by peak of net radiation and peak of $L E / R_{n}$ ratio. During the rainy season, AET for the paddy field and the cassava plantation ranged between 1 and $7 \mathrm{~mm}$. The range of AET for the teak plantation was between 2 and $6 \mathrm{~mm}$. The average contributions of latent heat flux to net radiation $\left(L E / R_{n}\right)$, actual evapotranspiration (AET) and reference evapotranspiration $\left(E T_{0}\right)$ in the three sites during the dry and rainy seasons are shown in table 1. In the rainy season, the average of AET was about $4 \mathrm{~mm}$ in all sites, although the variations of AET were different (paddy field: $\sigma=1.27$; cassava: $\sigma=1.42$; and teak: $\sigma=0.94$ ).

Table1. Daily average of actual evapotranspiration (AET), LE/ $\mathrm{R}_{\mathrm{n}}$ ratio and reference evapotranspiration $\left(E T_{0}\right)$ in the three measurement sites (D.S: Dry Season and R.S: Rainy Season).

\begin{tabular}{|c|c|c|c|c|c|c|}
\hline & \multicolumn{2}{|c|}{$\begin{array}{c}\text { AET } \\
\text { (Mm/daytime) }\end{array}$} & \multicolumn{2}{|c|}{$\left(L E / R_{n}\right) \%$} & \multicolumn{2}{|c|}{$\begin{array}{c}\mathrm{ET}_{0} \\
\text { (Mm/daytime) }\end{array}$} \\
\hline & D.S & R.S & D.S & R.S & D.S & R.S \\
\hline Paddy & 3.0 & 4.1 & 60 & 70 & 4.9 & 4.4 \\
\hline Cassava & 2.7 & 3.9 & 54 & 72 & 4.5 & 5.1 \\
\hline eak & 3.2 & 4.0 & 70 & 77 & 3.8 & 4.1 \\
\hline
\end{tabular}

This variation partly relates to the variation of $R_{n}$. In the dry season, the AET of the teak plantation showed less variation in comparison with the paddy field and cassava plantation (paddy field: $\sigma=0.99$; cassava: $\sigma=1.25$; teak: $\sigma=0.74$ ). In the dry season, the average amount of AET in the three sites was nearly the same, around $3 \mathrm{~mm}$; however, the average of $L E / R_{n}$ which mostly depends on the variation of $R_{n}$ showed different values (paddy $=60$, cassava: 54 and teak: 70 ). $\quad L E / R_{n}$ was almost the same about $70 \%$ during the rainy season for the paddy field and the cassava plantation, whereas the teak plantation had higher $L E / R_{n}$ of about $77 \%$ than the two other sites.

3.2. Crop coefficients for paddy field, cassava plantation and teak plantation
Figure2 shows the seasonal change of crop coefficients $\left(\mathrm{K}_{\mathrm{c}}\right)$ for the paddy field, cassava and teak plantations. The extreme maximum of $\mathrm{K}_{\mathrm{c}}$ factors in the paddy field, cassava and teak plantations which were observed in Sept. and Oct. were approximately $1.2,1.2$ and 1.3 , respectively. It decreased gradually thereafter in all sites and reached its minimum in Jan. And the average values for paddy field, cassava and teak plantations were $0.66,0.48$ and 0.76 , respectively.

During the growing season, the $\mathrm{K}_{\mathrm{c}}$ factor varied in the paddy field between 0.40 and 1.15 , and in the cassava plantation between 0.3 and 1.2. Variation of the $\mathrm{K}_{\mathrm{c}}$ factor in the teak plantation was smaller than those of the two other sites. For cassava, our extreme maximum of $\mathrm{K}_{\mathrm{c}}$ value was 1.2 in the end of Sept.
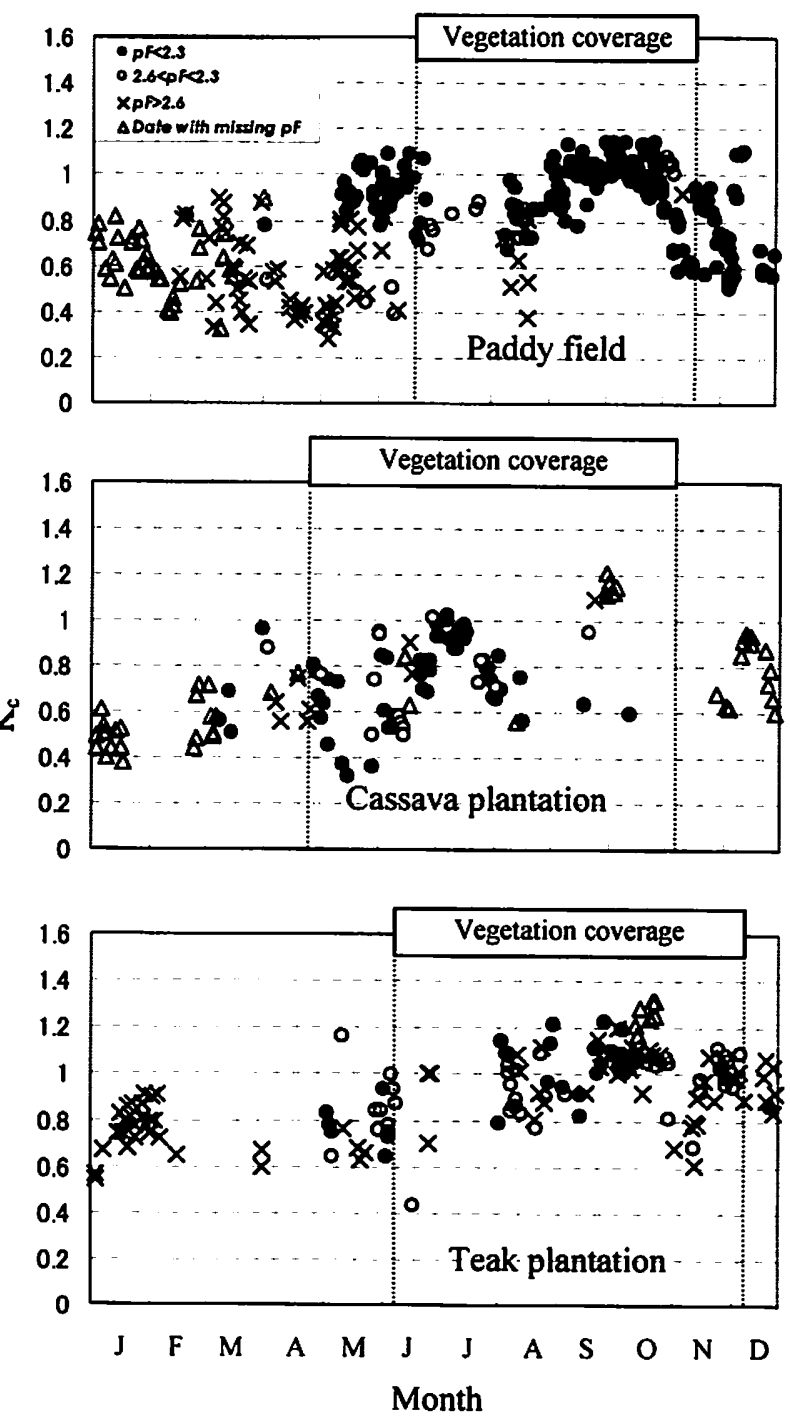

Fig.2. Change in crop coefficients for the paddy field, cassava and teak plantations.

According to Watanabe et al., (2004), the $\mathrm{K}_{\mathrm{c}}$ value in a cassava plantation which was planted in Nov. in Khon Kaen, Northeast Thailand, was about 1.2 in June. The difference of peak occurrence times may be attributed 
to the difference of planting months in two cassava fields. Data were classified to four groups based on soil moisture condition. Group 1 (closed circles), Group 2 (open circles), Group 3 (crosses) and Group 4 (triangles) correspond to the data obtained on days when the $\mathrm{pF}$ values at $15 \mathrm{~cm}$ are less than 2.3 , between 2.3 and 2.6, greater than 2.6 , and date with missing pF values, respectively. Cassava and teak plantations showed no tendency of soil moisture influence on the $\mathrm{K}_{\mathrm{c}}$ factor while the paddy field $\mathrm{K}_{\mathrm{c}}$ factor was affected by soil moisture. This fact implies that cassava plants and teak trees uptake water from deeper soil layers because of deeper root zones and that cassava and teak plantations are vegetations tolerable to drought.

\section{Conclusion}

During the rainy season, the range of AET in the paddy field and the cassava plantation was between 1 and $7 \mathrm{~mm} /$ daytime and in the teak plantation between 2 and $6 \mathrm{~mm} /$ daytime. The average amount of AET in the rainy season was nearly the same in the three sites. AET began to increase when the growing season started in May and reached its peak in Oct. or Sept. in all sites. During the dry season, the AET of teak plantation was around $3.2 \mathrm{~mm} /$ daytime, slightly higher than other sites. In the dry season, the average AET of the teak plantation showed no significant trend. During the rainy season, the $L E / R_{n}$ ratio in the paddy field and the cassava plantation were less than the teak plantation. Our results showed that the maximum $\mathrm{K}_{\mathrm{c}}$ factor in the paddy field, cassava and teak plantations was observed in Sept. and Oct. and that is a different month from other reports. The difference may be attributed to the difference of the planting month. Variation of the $K_{c}$ factor in the teak plantation was smaller than those of others. The $K_{c}$ factor in the paddy field was more affected by soil moisture than at the cassava and teak plantations suggesting that cassava plants and teak trees tolerate the water shortage during the dry season.

\section{Acknowledgments}

The authors would like to thank Professor Katumi Musiake, Fukushima University, Professor Toshio Koike, Tokyo University, and associate Professor Taikan OKI, Institute of Industrial Science, University of Tokyo for their financial support to accomplish this research.

\section{References}

Allen, R.G., Pereira, L.S., Raes, D., Smith, M., 1998: Crop evapotranspiration. Guidelines for Computing Crop Water Requirements. FAO Irrigation and Drainage Paper 56, FAO, Rome. Chapter 2, pp.2-10

Aoki, M., 1996: Estimation of Bowen ratio by climatic factors, Proceedings of international Conference on Evapotranspiration and Irrigation Scheduling, Nov. 4-7, San Antonio, Texas, USA. pp.341-346.

Casa. R., 2000: Estimation of evapotranspiration form a field of linseed in central Italy, Agricultural and forest meteorology, 104, pp.289-301

Peacock, C.E., 2004: Estimating evapotranspiration from a reed bed using the Bowen ratio energy balance method, Hydrological processes, 18, pp.247-260

Watanabe, K., 2004: Changes in seasonal evapotranspiration, soil water content, and crop coefficients in sugarcane, cassava, and maize fields in Northeast Thailand, Agricultural water management, 67, pp.133-143 